\title{
Characterization of new polyether-diols with different molar masses and modality prepared by ring opening polymerization of oxiranes initiated with anhydrous potassium hydroxide
}

\author{
Zbigniew Grobelny $^{1} \cdot$ Sylwia Golba ${ }^{2} \cdot$ Justyna Jurek-Suliga ${ }^{2}$
}

Received: 24 July 2018 / Accepted: 5 February 2019 / Published online: 23 February 2019

(C) The Author(s) 2019

\begin{abstract}
Several new polyether-diols were prepared by ring-opening polymerization of monosubstituted oxiranes in the presence of anhydrous potassium hydroxide. 1,2-Butylene oxide (BO), styrene oxide (SO), isopropyl glycidyl ether (IPGE), allyl glycidyl ether (AGE), phenyl glycidyl ether (BGE), p-methoxyphenyl glycidyl ether (MPGE) and benzyl glycidyl ether (BGE) were chosen as monomers. Macrocyclic ligands complexing metal cations, i.e. coronand 18C6 or cryptand C222 were used as activators in these systems. All polymerizations were carried out in tetrahydrofuran solution at room temperature. Molar mass $\left(\mathrm{M}_{\mathrm{n}}\right)$ and dispersity $\left(\mathrm{M}_{\mathrm{w}} / \mathrm{M}_{\mathrm{n}}\right)$ of the polymers obtained with $\mathrm{KOH}$ depends on the kind of monomer, initial concentration of the initiator and the presence and kind of ligand or water. For example, PBO-diols prepared without ligand are bimodal and for the main fraction $\mathrm{M}_{\mathrm{n}}>\mathrm{M}_{\text {calc }}$. However, after addition of $18 \mathrm{C} 6$ polymers are unimodal and unexpectedly have much higher $\mathrm{M}_{\mathrm{n}}=$ $13,700-15,800$ and very low dispersity $\left(\mathrm{M}_{\mathrm{w}} / \mathrm{M}_{\mathrm{n}}=1.04-1.08\right) . \mathrm{M}_{\mathrm{n}}$ of PBO-diols decrease with increase of $[\mathrm{KOH}]_{\mathrm{o}}$ and do not change at $[\mathrm{BO}]_{\mathrm{o}}=2.0-9.0 \mathrm{~mol} / \mathrm{dm}^{3}$. Addition of C222 results in $\mathrm{M}_{\mathrm{n}}$ decrease of PBO-diols. Similar effects were observed in the polymerization of PAGE-diols and PPGE-diols. In the polymerization of SO, PGE, MPGE and BGE initiator efficiency $(f)$ is high and $\mathrm{M}_{\mathrm{n}}<\mathrm{M}_{\text {calc }}$. Polymodality of some polymers obtained was discussed in term of the formation of various species propagating with different rate constants.
\end{abstract}

Keywords Polymer synthesis $\cdot$ Anhydrous potassium hydroxide $\cdot$ Ring opening polymerization $\cdot$ Monosubstituted oxiranes · Polyether-diols

\section{Introduction}

Polyethers, especially poly(propylene oxide)s belong to important class of polymers due to their thermal and chemical stability as well physical and mechanical properties resulting in wide applications such as impact modifiers, surfactants, deemulsifiers, dispersant agents, fuel additives, wetting agents, lubricants, rheological modifiers, biomedical materials and adhesives [1-7]. Polyether-diols, i.e. homo- and copolymers prepared from ethylene oxide (EO), propylene oxide (PO) or

Zbigniew Grobelny

zbigniew.grobelny@us.edu.pl

1 Institute of Chemistry, University of Silesia, 40-007 Katowice, Poland

2 Institute of Materials Science, University of Silesia, 40-007 Katowice, Poland 1,2-butylene oxide (BO) are very useful components in the fabrication of polyurethane elastomers or foams [8].

Propylene oxide have been polymerized by many procedures involving ring-opening polymerization (ROP) in bulk [9-11]. The most popular anionic initiators used are alkali metal alkoxides or hydroxides. It was observed, that $\mathrm{KOH}$, $\mathrm{RbOH}$ and $\mathrm{CsOH}$ are effective initiators, while $\mathrm{LiOH}$ and $\mathrm{NaOH}$ are ineffective ones, probably due to their very low solubility in liquid monomer [12].

It was established by Steiner et al. [13], that PO polymerization initiated by solid anhydrous $\mathrm{KOH}$ is not surface-catalyzed. On the other hand, Pluciński et al. [14] assumed later, that this polymerization may be initiated both homogeneously and on the surface of $\mathrm{KOH}$. The polymerization proceeds readily in bulk at $30{ }^{\circ} \mathrm{C}$ and the product obtained had high unsaturation and molar mass $\left(\mathrm{M}_{\mathrm{n}}\right)$ about 5000 regardless of the monomer-to-catalyst ratio [13]. During the polymerization in tetrahydrofuran (THF) solution great amount of macromolecules with unsaturated starting groups also appears, resulting 
from deprotonation of the monomer mainly by initiator [15]. This side reaction is undesired, because it causes formation of monool fraction and decrease $M_{n}$ of the polymers obtained. It was stated, that addition of water and complexing agent 18crown-6 (18C6) strongly reduced PPOs unsaturation [15]. PPO-diols with very low unsaturation are synthesized in industry by bulk polymerization of $\mathrm{PO}$ in the presence of $\mathrm{KOH} /$ 1,2-propylene glycol system at $105-125^{\circ} \mathrm{C}$ and $0.3-0.5 \mathrm{MPa}$ $[8,16]$. Similar kind of initiator, i.e. monopotassium salt of dipropylene glycol activated by $18 \mathrm{C} 6$ was recently used for preparation of polystyrene-diols in THF solution at room temperature [17]. PPO was also used as a component of bifunctional polymeric activators (PACs) used for ROP of the $\varepsilon \mathrm{CL}$ monomer, which influenced on the phase behavior of the synthesized copolymers and hence their the mechanical properties and the crystallinity degree [18].

Polyether-diols derived from some glycidyl ethers were obtained by Stolarzewicz $[19,20]$. The author investigated the influence of dimethylsulfoxide and its mixtures with anisole on the $\mathrm{KOH}$ - initiated polymerization of $o$ chlorophenyl glycidyl ether [19]. It was concluded, that both solid and dissolved $\mathrm{KOH}$ are indispensable for initiating the polymerization with initial reaction step taking place on the surface of the solid $\mathrm{KOH}$. It can be assumed, that the sorption of the monomer takes place on the surface of the undissolved $\mathrm{KOH}$. The adsorbed monomer then reacts with a dissolved $\mathrm{KOH}$ molecule, which leads to ring opening and initiation of the polymerization. Moreover, in the series of chlorophenyl glycidyl ethers polymerization, involving monomers with different number of chlorine atoms, in the presence of $\mathrm{KOH}$ the substituent effect attention was paid to decrease of the basicity of the reaction mixture during the polymerization [20]. This phenomenon was assigned to lability of chlorine atoms bonded to the aromatic ring and on additional consumption of the initiator in the reaction with $\mathrm{Cl}$-substituted monomer leading to $\mathrm{OH}$-substituted ones.

Other examples of polyether-diols involve copolyetherdiols synthesized from various oxiranes, i.e. block copolymers PO-EO with terminal PEO blocks, block copolymers PO-EO with internal PEO blocks and random copolymers PO-EO [8]. They are used especially for polyurethane elastomers, coatings, adhesives and sealants [21,22]. The most extensively studied triblock copolyether-diol is $\mathrm{PEO} / \mathrm{PPO} /$ $\mathrm{PEO}$, polymeric nonionic surfactant, which is commercially available as Pluronics (BASF) or Synperonics (ICI) [23]. In this polymers PPO builds the hydrophobic block, whereas PEO two hydrophilic blocks. Then, a number of ABA and $\mathrm{BAB}$ triblock copolymers of ethoxyethyl glycidyl ether and $\mathrm{PO}$ were prepared by sequential anionic polymerization initiated with dicesium salt of 1,2-propylene glycol [24]. It was stated, that these copolymers can form nanosized aggregates and exhibit different temperature behavior, depending on the copolymer architecture. However, data concerning synthesis and application of other polyetherdiols are rather scarce [8].

The aim of the present work was characterization of several new polyether-diols prepared in anionic ring-opening polymerization of other monosubstititued oxiranes initiated with anhydrous $\mathrm{KOH}$, which till now was applied mainly for polymerization of propylene oxide [13-15]. Some of them may be interesting as substrates for the synthesis of new thermoplastic polyurethanes. 1,2-Butylene oxide (BO), styrene oxide (SO) and some glycidyl ethers, such as isopropyl glycidyl ether (IPGE), allyl glycidyl ether (AGE), phenyl glycidyl ether (PGE), $p$-methoxyphenyl glycidyl ether (MPGE) and benzyl glycidyl ether were chosen as monomers. All polymerizations were carried out in THF solution and mild conditions, i.e. room temperature and normal pressure. The influence of initial concentration of the monomer, initiator, the presence of water and kind of macrocyclic ligand complexing counterion (L), i.e. coronand $18 \mathrm{C} 6$ or cryptand $\mathrm{C} 222$ on molar mass, dispersity and modality of the prepared polyether-diols were studied and discussed. ${ }^{13} \mathrm{C}$ NMR, MALDI-TOF and SEC techniques were used for analysis of the polymers. We decided to develop the studies taking into account that data concerning polymerization of mentioned oxiranes with anhydrous $\mathrm{KOH}$ are scare. The present results concerning the influence of mentioned parameters on molar masses and modality of synthesized polyether-diols are novel and develop our knowledge about anionic polymerization of oxiranes.

\section{Experimental}

\section{Materials}

Monomers, i.e. 1,2-butylene oxide, styrene oxide, isopropyl glycidyl ether, allyl glycidyl ether, phenyl glycidyl ether, $p$ methoxyphenyl glycidyl ether and benzyl glycidyl ether (all from Aldrich) were dried over $\mathrm{CaH}_{2}$ and distilled at $336 \mathrm{~K}$ $\left(63{ }^{\circ} \mathrm{C}\right), 467 \mathrm{~K}\left(194{ }^{\circ} \mathrm{C}\right), 414 \mathrm{~K}\left(131{ }^{\circ} \mathrm{C}\right), 427 \mathrm{~K}\left(154^{\circ} \mathrm{C}\right)$, $518 \mathrm{~K}\left(245^{\circ} \mathrm{C}\right), 350 \mathrm{~K}\left(77^{\circ} \mathrm{C}\right) / 10$ Torr and $344 \mathrm{~K}\left(71^{\circ} \mathrm{C}\right) /$ 11 Torr, respectively. Anhydrous tetrahydrofuran (THF) (Acros Organics) was kept over $\mathrm{CaH}_{2}$ and distilled at $339 \mathrm{~K}$ $\left(66{ }^{\circ} \mathrm{C}\right)$. Potassium hydride $(\mathrm{KH})$ was purified according to the procedure described by Brown [25]. A $35 \mathrm{wt}-\%$ dispersion of $\mathrm{KH}$ in mineral oil (Aldrich) was mixed with $n$-pentane in a dry argon atmosphere and then decanted. This was repeated three times followed by a three-fold washing with dry THF. Finally, THF was evaporated in vacuum. Coronand 18C6 $(1,4,7,10,13,16$-hexaoxacyclooctadecane) (Merck) and cryptand C222 $(4,7,13,16,21,24$-hexaoxa-1,10diazabicyclo[8,8,8]hexacosane) (Merck) were used without purification. 
Table 1 Characterization of polyether-diols prepared in the polymerization of $\mathrm{BO}$ initiated with anhydrous $\mathrm{KOH} ;[\mathrm{BO}]_{\mathrm{o}}=$ $2.0 \mathrm{~mol} / \mathrm{dm}^{3}$

\begin{tabular}{|c|c|c|c|c|c|c|}
\hline No. & {$[\mathrm{KOH}]_{\mathrm{o}}\left(\mathrm{mol} / \mathrm{dm}^{3}\right)$} & $\mathrm{M}_{\text {calc }}^{\mathrm{a} /}$ & Yield (\%) & $\mathrm{M}_{\mathrm{n}}(\mathrm{SEC})$ & $\mathrm{M}_{\mathrm{w}} / \mathrm{M}_{\mathrm{n}}(\mathrm{SEC})$ & Time of reaction (h) \\
\hline \multirow[t]{2}{*}{1} & \multirow[t]{2}{*}{0.05} & \multirow[t]{2}{*}{5769} & (a) 90 & 10,700 & 1.06 & \multirow[t]{2}{*}{480} \\
\hline & & & (b) 10 & 2500 & 1.20 & \\
\hline \multirow[t]{2}{*}{2} & \multirow[t]{2}{*}{0.10} & \multirow[t]{2}{*}{2884} & (a) 96 & 6400 & 1.07 & \multirow[t]{2}{*}{410} \\
\hline & & & (b) 4 & 950 & 1.06 & \\
\hline \multirow[t]{2}{*}{3} & \multirow[t]{2}{*}{0.15} & \multirow[t]{2}{*}{1923} & (a) 95 & 4400 & 1.06 & \multirow[t]{2}{*}{390} \\
\hline & & & (b) 5 & 900 & 1.02 & \\
\hline
\end{tabular}

${ }^{\mathrm{a} /} \mathrm{M}_{\text {calc }}=2\left([\mathrm{BO}]_{\mathrm{o}} /[\mathrm{KOH}]_{\mathrm{o}}\right) \mathrm{M}_{\mathrm{BO}}$ (when one propagating macromolecule has two alkoxide centers)

\section{Synthesis}

All syntheses were performed at $20^{\circ} \mathrm{C}$ in a $50 \mathrm{~cm}^{3}$ reactor equipped with a magnetic stirrer and a Teflon valve enabling substrates delivery and sampling under argon atmosphere. Potassium hydroxide was obtained in the reaction of potassium hydride with distilled water dissolved in tetrahydrofuran. In the first series of polymerizations of 1,2butylene oxide the initial concentration of the monomer was equal to $2.0 \mathrm{~mol} / \mathrm{dm}^{3}$ and the initial amount of potassium hydroxide was $0.28,0.56$ or $0.84(0.05,0.10$ and $0.15 \mathrm{~mol} / \mathrm{dm}^{3}$, respectively). For example, potassium hydride $(0.08 \mathrm{~g}, 2.0 \mathrm{mmol})$ and tetrahydrofuran $\left(16.5 \mathrm{~cm}^{3}\right)$ was introduced into the reactor and then water $(0.036 \mathrm{~g}$, $2.0 \mathrm{mmol}$ ) was added by use of microsyringe. The reaction mixture was stirred during $2 \mathrm{~h}$ until all hydrogen $\left(44.7 \mathrm{~cm}^{3}\right)$ was evolved. It resulted in a fine dispersion of pure anhydrous potassium hydroxide in the ether medium. That system was used as the initiator when 1,2-butylene oxide $\left(3.5 \mathrm{~cm}^{3}, 0.42 \mathrm{~g}, 40 \mathrm{mmol}\right)$ was introduced into the reactor. The reaction mixture was then stirred during several days. After complete conversion of the monomer the reaction mixture was neutralized with $\mathrm{HCl} / \mathrm{H}_{2} \mathrm{O}$ system $\left(0.1 \mathrm{~mol} / \mathrm{dm}^{3}, 50 \mathrm{~cm}^{3}\right)$ and transferred to the separator containing chloroform $\left(70 \mathrm{~cm}^{3}\right)$. After shaking during $5 \mathrm{~min}$, two layers were formed, i.e. interferior polyether layer and superior layer containing water and the potassium salt. These layers were separated and the superior layer was removed. After three washings with distilled water, polyether was obtained by evaporating of chloroform and water in vacuum. In the next series of polymerizations $\mathrm{KOH}$ was obtained in the reaction of $\mathrm{KH}$ with $\mathrm{H}_{2} \mathrm{O}$ in the presence of $18 \mathrm{C} 6(0.53 \mathrm{~g}, 2.0 \mathrm{mmol})$ or $\mathrm{KH} / \mathrm{C} 222(0.75 \mathrm{~g}$, $2.0 \mathrm{mmol})$. Initiator $\mathrm{KOH} / 18 \mathrm{C} 6 / \mathrm{H}_{2} \mathrm{O}(1 / 1 / 0.5)$ was prepared in the reaction of $\mathrm{KH} / 18 \mathrm{C} 6$ with $0.054 \mathrm{~g}(3.0 \mathrm{mmol})$ $\mathrm{H}_{2} \mathrm{O}$. Similar procedure was applied for polymerization of other oxiranes. The concentration of monomer during polymerization was monitored by the 1,4-dioxane method [26]. The final conversions were $\sim 99 \%$. The yields of the reactions were $97-99 \%$. Almost all investigated processes were heterogeneous and initiators were present at the end of the polymerization.

\section{Measurements}

$100 \mathrm{MHz}{ }^{13} \mathrm{C}$ NMR spectra were recorded in $\mathrm{CDCl}_{3}$ at $25^{\circ} \mathrm{C}$ on a Bruker Avance 400 pulsed spectrometer equipped with $5 \mathrm{~mm}$ broad-band probe and applying Waltz16 decoupling sequence. Chemical shifts were referenced to tetramethylsilane serving as an internal standard. To obtain a good spectrum of the polymer main chain exhibiting its microstructural details about 3000 scans were satisfactory but in order to observe the signals of the polymer chain ends more than 10,000 scans were necessary. Molar masses and dispersities of polymers were obtained by means of size exclusion chromatography (SEC) on a Shimadzu Prominance UFLC instrument at $40{ }^{\circ} \mathrm{C}$ on a Shodex $300 \mathrm{~mm} \times 8 \mathrm{~mm}$ OHpac column using tetrahydrofuran as a solvent. Polystyrenes were used as calibration standards. MALDITOF spectra were recorded on a Shimadzu AXIMA Performance instrument. Dithranol was used as a matrix.

\section{Results and discussion}

The results presented below concern the most important and interesting phenomena observed in the polymerization of chosen oxiranes initiated with anhydrous $\mathrm{KOH}$. Precisely four kinds of initiators were applied, namely pure $\mathrm{KOH}$ in the form

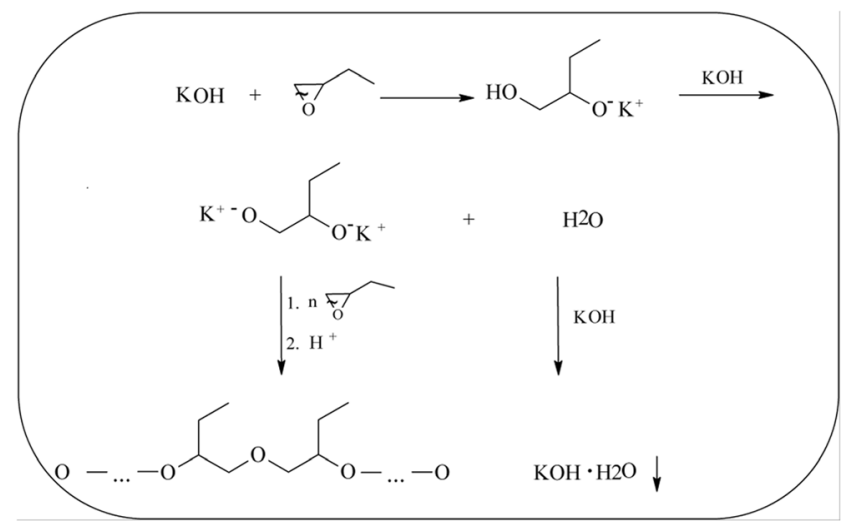

Fig. 1 Polymerization of 1,2-butylene oxide (BO) initiated with anhydrous $\mathrm{KOH}$ in tetrahydrofuran 
Fig. 2 MALDI-TOF spectrum of PBO-diol (3) obtained in the presence of anhydrous $\mathrm{KOH}$
1194.8

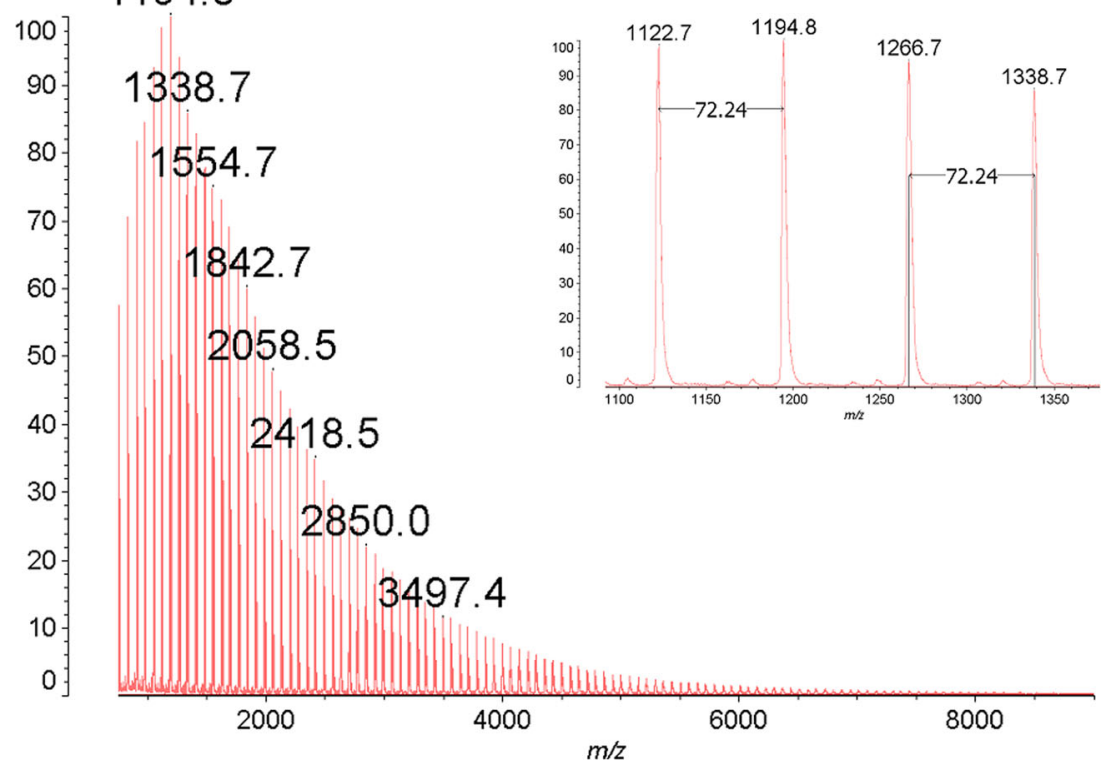

of dispersion, $\mathrm{KOH}$ activated by coronand $18 \mathrm{C} 6$, partially hydrated $\mathrm{KOH}$ activated by $18 \mathrm{C} 6$ and $\mathrm{KOH}$ activated by cryptand $\mathrm{C} 222$.

\section{Polymerisation of 1,2-butylene oxide}

It was interesting whether initiation is mediated by $\mathrm{KOH}$ solubilized in the reaction mixture or on crystal surface. Table 1 presents SEC results concerning heterogeneous polymerization of 1,2-butylene oxide (BO) carried out at various initial amount of $\mathrm{KOH}$.

It was assumed, that $\mathrm{KOH}$ reacts in the system by two ways, i.e. ring opening (RO) of the monomer and deprotonation of $\mathrm{OH}$ group. $\mathrm{RO}$ results in hydroxyalkoxide formation, while deprotonation of $\mathrm{OH}$ group leads to $\mathrm{OK}$ ones and further to $\mathrm{H}_{2} \mathrm{O}$ and dialkoxide, which mediates chain propagation in two directions. It was also postulated, that interaction of $\mathrm{KOH}$ with $\mathrm{H}_{2} \mathrm{O}$ leads to the formation of hydrate $\mathrm{KOH}$. $\mathrm{H}_{2} \mathrm{O}$. It was stated in additional experiment, that hydrate $\mathrm{KOH} \cdot \mathrm{H}_{2} \mathrm{O}(1 / 1)$ is insoluble in the reaction mixture and does not initiate $\mathrm{BO}$ polymerization, similarly as it was observed previously for PO [15]. The course of the polymerization was presented on Fig. 1.

Formation of PBO-diol macromolecules was confirmed by MALDI-TOF analysis of polymers. Figure 2 shows spectrum of exemplary polymer (3).

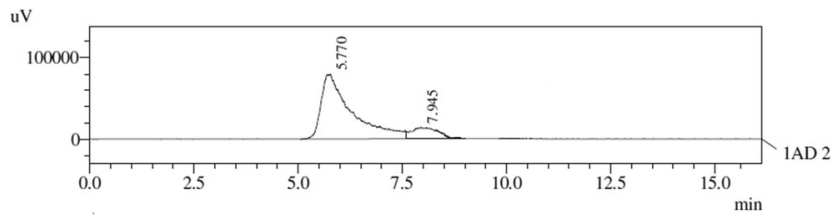

Fig. 3 SEC chromatogram of PBO-diol (1) prepared by use of anhydrous $\mathrm{KOH}$
Spectrum at $\mathrm{m} / \mathrm{z} 900$ to 6000 reveals signals, which belong exclusively to macromolecules containing central oxygen at$\mathrm{om}$ and two terminal $\mathrm{OH}$ groups. These macromolecules form adducts with sodium ions. For example, signals at $m / z$ 1554.7; 2130.2 and 2778.1 represents macromolecules, which contain 21,29 and 38 mers of BO, respectively $\left(\mathrm{M}_{\text {calc }}=1555.3\right.$; 2132.2 and 2781.2, respectively).

${ }^{13} \mathrm{C}$ NMR spectrum of this polymer reveals carbon signals of $\mathrm{CH}_{2}$ (at 71.5-72.5 ppm) and $\mathrm{CH}$ (at 80.6-81.0 ppm) groups in polymer chain as well as $\mathrm{CH}_{3}$ (at 9.9 ppm) and $\mathrm{CH} 2$ (at $24.9 \mathrm{ppm}$ ) groups present in substituents. Weak signal of $\mathrm{CH}\left(\mathrm{CH}_{2} \mathrm{CH}_{3}\right) \mathrm{OH}$ terminal groups was detected at $74.1 \mathrm{ppm}$. However, none signals at 90-150 ppm were observed, which indicated the lack of unsaturation, resulting from deprotonation of monomer with initiator and chain transfer reaction.

It is worth noting, that prepared PBO-diols are bimodal and have low dispersities (Table 1, Fig. 3).

Analyzing polymerization of some oxacyclic compounds, Penczek et al. [27] confirmed the possibility of occurrence of bimodal molar mass distribution. They stated that in the polymerization process bimodality exclusively appeared, when there were two species propagating with different rate constants and that these species did not exchange fast enough. Therefore, we propose, that in the polymerization of $\mathrm{BO}$ initiated with $\mathrm{KOH}$ two kinds of alkoxide centers with different

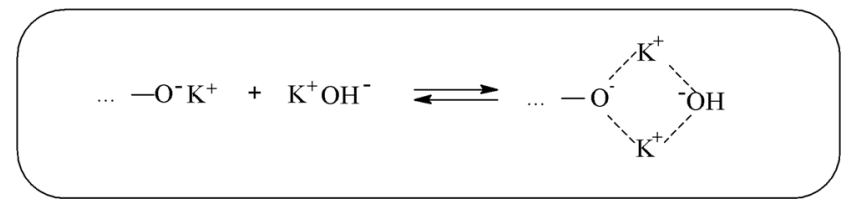

Fig. 4 Possible ionic aggregates (shown as products) with low reactivity formed during $\mathrm{BO}$ polymerization with $\mathrm{KOH}$ in THF solution 
Table 2 Characterization of polyether-diols prepared in the polymerization of BO initiated with anhydrous $\mathrm{KOH}$ activated by $18 \mathrm{C} 6$; $[\mathrm{KOH}]_{\mathrm{o}}=[18 \mathrm{C} 6]_{\mathrm{o}} ;\left[\mathrm{H}_{2} \mathrm{O}\right]_{\mathrm{o}}=0.05 \mathrm{~mol} / \mathrm{dm}^{3}$

\begin{tabular}{|c|c|c|c|c|c|c|c|c|c|}
\hline No. & Initiating system & {$[\text { Monomer }]_{\mathrm{o}}\left(\mathrm{mol} / \mathrm{dm}^{3}\right)$} & {$[\mathrm{KOH}]_{\mathrm{o}}\left(\mathrm{mol} / \mathrm{dm}^{3}\right)$} & Yield (\%) & $\mathrm{M}_{\text {calc }}$ & $\mathrm{M}_{\mathrm{n}}(\mathrm{SEC})$ & $\mathrm{M}_{\mathrm{w}} / \mathrm{M}_{\mathrm{n}}(\mathrm{SEC})$ & $\operatorname{IE}(f)^{2 /}$ & Time of reaction $(\mathrm{h})$ \\
\hline 4 & $\mathrm{KOH} / 18 \mathrm{C} 6$ & 2.0 & 0.05 & 99 & 5769 & 15,800 & 1.04 & 0.37 & 288 \\
\hline 5 & $\mathrm{KOH} / 18 \mathrm{C} 6$ & 2.0 & 0.10 & 99 & 2884 & 14,800 & 1.05 & 0.19 & 240 \\
\hline 6 & $\mathrm{KOH} / 18 \mathrm{C} 6$ & 2.0 & 0.15 & 98 & 1923 & 13,700 & 1.08 & 0.14 & 210 \\
\hline 7 & $\mathrm{KOH} / 18 \mathrm{C} 6 / \mathrm{H}_{2} \mathrm{O}$ & 2.0 & 0.10 & 97 & $2884^{1 /}$ & 8500 & 1.31 & - & 520 \\
\hline 8 & $\mathrm{KOH} / 18 \mathrm{C} 6$ & 5.0 & 0.10 & 99 & 7210 & 16,000 & 1.05 & 0.45 & 275 \\
\hline 9 & $\mathrm{KOH} / 18 \mathrm{C} 6$ & 9.0 & 0.10 & 98 & 12,978 & 16,500 & 1.05 & 0.79 & 450 \\
\hline
\end{tabular}

${ }^{1 /}$ the influence of chain transfer reaction with $\mathrm{H}_{2} \mathrm{O}$ on molar mass was omitted

2/ IE - initiator efficiency, $f=\mathrm{M}_{\text {calc }} / \mathrm{M}_{\mathrm{n}}(\mathrm{SEC})$,

reactivity are formed (Fig. 4) and they are responsible for the observed bimodality.

However, molar masses of the main fractions of PBOs (13 ) are higher than calculated ones. It means, that part of initiator remains inactive and does not initiate polymerization. It involves insoluble $\mathrm{KOH}$ present in crystal lattice as well as hydrate $\mathrm{KOH} \cdot \mathrm{H}_{2} \mathrm{O}$. Moreover, $\mathrm{M}_{\mathrm{n}}$ of both fractions depends on initial amount of $\mathrm{KOH}$ in the system, i.e. decrease with $[\mathrm{KOH}]_{\mathrm{o}}$. This result differs strongly from that observed by Steiner et al. [13] in the polymerization of PO carried out in similar conditions. In that case $\mathrm{M}_{\mathrm{n}}$ of PPOs was independent on the amount of $\mathrm{KOH}$ used for initiation. Even at a catalystto-propylene oxide mole ratio of one there was no significant change in reaction rate nor in product characteristic. The author assumed, that the polymerization proceeds in this case as a process initiated by $\mathrm{KOH}$ dissolved partly in the monomer. However, Pluciński [14] proposed, that PO polymerization may be initiated both homogeneously and on the surface of $\mathrm{KOH}$. Similar effect was reported by Stolarzewicz [19] for $o$ chlorophenyl glycidyl ether. The results obtained by us for BO polymerization lead to the same conclusions. Concentration of $\mathrm{KOH}$ solubilised in the reaction mixture is rather low and constant in the polymerization (1)-(3). However, molar masses of the polymers decrease distinctly with increase of initial amount of $\mathrm{KOH}$. It indicates, that initiation of the polymerization may occur also on the crystal surface of anhydrous $\mathrm{KOH}$.

Unexpectedly, application of coronand 18C6, which forms strong complexes with $\mathrm{K}^{+}$results in distinct shortening of polymerization time and increase of polymers molar masses (4-6) (Table 2). This effect could be explained by appearance

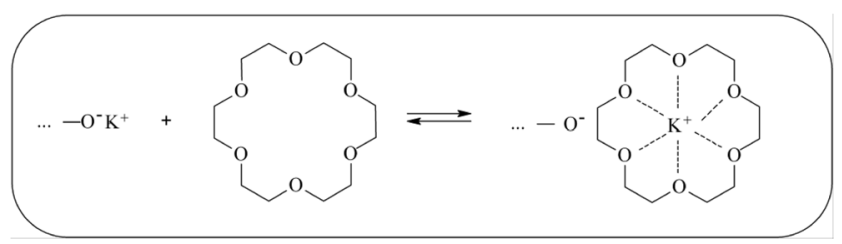

Fig. 5 Activation of alkoxide centre of growing chain by formation of flat complex of coronand $18 \mathrm{C} 6$ with $\mathrm{K}^{+}$ of ligand separated highly reactive ion pairs in growing chains existing in equilibrium with contact ion pairs [28] (Fig. 5). Rate of propagation on the former is much higher than on the latter.

Molar masses of polymers (4-6) decrease with increase of $\mathrm{KOH} / 18 \mathrm{C} 6$ amount in the system. Addition of some amount of $\mathrm{H}_{2} \mathrm{O}$ to (5) decreases markedly $\mathrm{M}_{n}$ of polymer (7) due to chain transfer reaction to water. All polymers in this series are unimodal (Fig. 6) and have low dispersity $\left(\mathrm{M}_{\mathrm{w}} / \mathrm{M}_{\mathrm{n}}=1.04\right.$ 1.08), except polymer (7), which has relatively high dispersity $\left(\mathrm{M}_{\mathrm{w}} / \mathrm{M}_{\mathrm{n}}=1.31\right)$.

Interestingly, molar masses of the polymers synthesized at much higher initial concentration of the monomer, i.e. 5.0 (8) and $9.0 \mathrm{~mol} / \mathrm{dm}^{3}$ (9) have similar values. Increase of [BO $]_{\mathrm{o}}$ from 2.0 (5) to $9.0 \mathrm{~mol} / \mathrm{dm}^{3}$ (9) results only in small increase of polymers $M_{n}$, i.e. from 14,800 to 16,300 for polymers prepared at the same $[\mathrm{KOH}]_{\mathrm{o}}=0.10 \mathrm{~mol} / \mathrm{dm}^{3}$. This effect could be explained by high increase of initiator efficiency $(f)$ caused probably by higher polarity of the medium. It is also worth noting, that dispersity of the polymers $(4,5,8$ and 9$)$ is very low $\left(\mathrm{M}_{\mathrm{w}} / \mathrm{M}_{\mathrm{n}}=1.04-1.05\right)$ and independent on initial concentration of monomer.

Polymers (10-12) synthesized in the presence of cryptand C222 have molar masses about two-times lower, than these

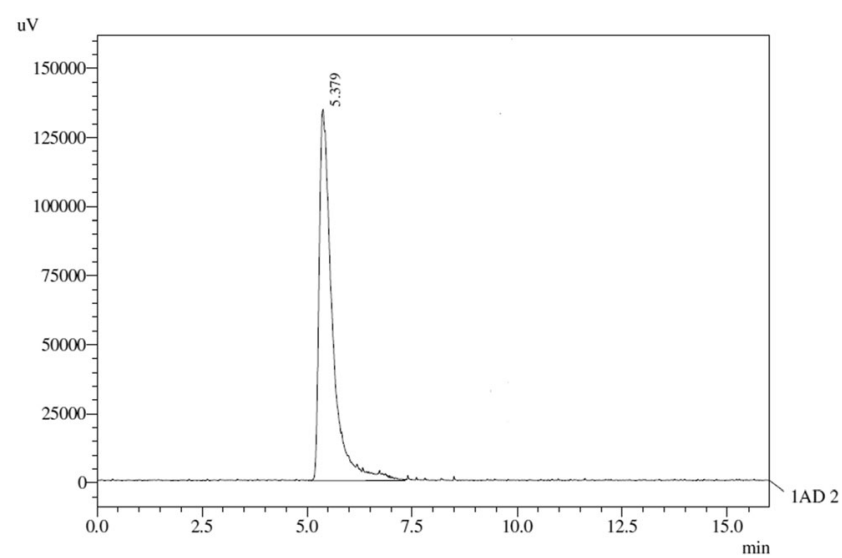

Fig. 6 SEC chromatograms of PBO-diols (5) prepared by use of anhydrous $\mathrm{KOH}$ activated by $18 \mathrm{C} 6$ 
Table 3 Characterization of polyether-diols prepared in the polymerization of $\mathrm{BO}$ initiated with anhydrous $\mathrm{KOH}$ activated by $\mathrm{C} 222$; $[\mathrm{KOH}]_{\mathrm{o}}=[\mathrm{C} 222]_{\mathrm{o}} ;[\mathrm{BO}]_{\mathrm{o}}=2.0 \mathrm{~mol} / \mathrm{dm}^{3}$

\begin{tabular}{lllllllll}
\hline No. & Initiating system & {$[\mathrm{KOH}]_{\mathrm{o}}\left(\mathrm{mol} / \mathrm{dm}^{3}\right)$} & $\mathrm{M}_{\text {calc }}$ & Yield (\%) & $\mathrm{M}_{\mathrm{n}}(\mathrm{SEC})$ & $\mathrm{M}_{\mathrm{w}} / \mathrm{M}_{\mathrm{n}}(\mathrm{SEC})$ & IE $(f)$ & Time of reaction (h) \\
\hline 10 & $\mathrm{KOH} / \mathrm{C} 222$ & 0.05 & 5769 & (a) 30 & 7700 & 1.01 & - & - \\
& & & (b) 32 & 5500 & 1.01 & - & 190 \\
11 & $\mathrm{KOH} / \mathrm{C} 222$ & 0.10 & 2884 & 99 & 7500 & 1.32 & 0.38 & 150 \\
12 & $\mathrm{KOH} / \mathrm{C} 222$ & 0.15 & 1923 & 98 & 5100 & 1.56 & 0.38 & 110 \\
\hline
\end{tabular}

for polymers prepared with 18C6 (Table 3). It probably results from increased solubility of initiator in the presence of $\mathrm{C} 222$, the strongest ligand for $\mathrm{K}^{+}$[29]. Alkoxide anion practically does not interact with potassium cation complexed by $\mathrm{C} 222$ (Fig. 7). Interestingly, at lowest $[\mathrm{KOH}] \mathrm{o}$ three fractions of polymer (10) are obtained (Fig. 8).

Dispersity of polymers needs some comments. In general, $\mathrm{M}_{\mathrm{w}} / \mathrm{M}_{\mathrm{n}}$ values are very low, e.g. 1.04-1.08 for polymers obtained in the presence of $18 \mathrm{C} 6$. Addition of $\mathrm{H}_{2} \mathrm{O}$ distinctly increases dispersity to 1.31 . Polymers prepared in the presence of C222 are polymodal or have relatively high dispersity (1.32-1.56).

\section{Polymerisation of styrene oxide}

In the course of polymerization of styrene oxide (SO) initiated with $\mathrm{KOH}$ activated by $18 \mathrm{C} 6$ the reaction mixture are dark red and homogeneous. Polymer (13) obtained at lower $[\mathrm{SO}]_{\mathrm{o}}$ is unimodal, whereas that prepared at higher $[\mathrm{SO}]_{\mathrm{o}}$ is bimodal (14) (Table 4). Polymers have relatively high dispersity and $\mathrm{M}_{\mathrm{n}}$ of the polymers are lower than $\mathrm{M}_{\text {calc }}$.

It was proposed, that initiation occurs quantitatively in this case, due to high solubility of $\mathrm{KOH}$ in the reaction mixture. It was assumed that in this case free water does not form hydrate with $\mathrm{KOH}$ and remains in the solution. During the polymerization chain transfer reaction to water occurs, which lowering $M_{n}$ of the polymers obtained (Fig. 9).

MALDI-TOF spectrum of polymer (14) shown in Fig. 10 reveals one series of signals at $\mathrm{m} / \mathrm{z} 521.6$ to 4476.8 , which belongs to macromolecules containing central oxygen atom and two terminal $\mathrm{OH}$ groups. For example, signals at $\mathrm{m} / \mathrm{z}$

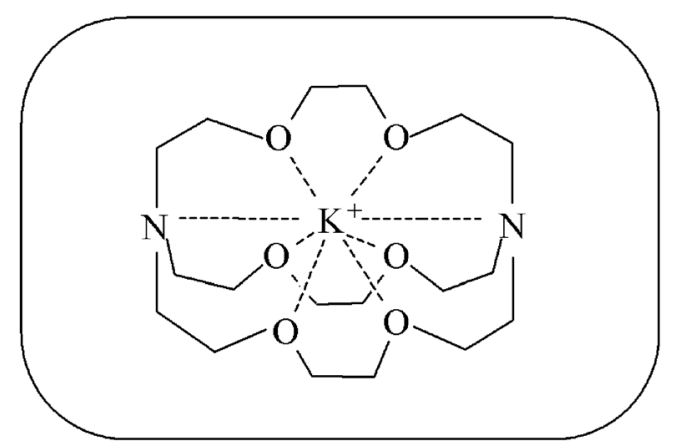

Fig. 7 Potassium cation encapsulated by bicyclic ligand C222
$762.4,2322.1$ and 3400.6 represents macromolecules which contain 6, 19 and 28 mers of the monomer, respectively $\left(\mathrm{M}_{\text {calc }}=761.9,2323.8\right.$ and 3405.2, respectively $)$. These macromolecules form adducts with sodium ions.

Styrene oxide is monosubstituted oxirane, which possesses acidic hydrogen atom in the molecule. It is responsible for deprotonation of the monomer by initiator and alkoxide centre of growing chain (chain transfer reaction), which occurs as side reactions in anionic polymerization of theses oxiranes. Recently, we reported [17], that PSOs prepared in polymerization initiated with potassium alkoxides indicates some unsaturation, resulting from deprotonation of methine group (and not methylene ones) present in SO molecule. Signals of carbons of unsaturated starting groups $\mathrm{CH}_{2}=\mathrm{C}(\mathrm{Ph}) \mathrm{O}-$ were observed at 133.02 and $159.66 \mathrm{ppm}$ in ${ }^{13} \mathrm{C} \mathrm{NMR}$ spectrum. However, these signals were not detected in the spectra of PSO-diols obtained in this work. Evidently, chain transfer to water is much faster than to the monomer, which results in lack of polymers unsaturation.

\section{Polymerisation of glycidyl ethers}

Formation of bimodal polymers is also observed in the polymerization of allyl glycidyl ether (AGE) initiated in the presence of $\mathrm{KOH}$ without ligand (15) (Table 5).

Similarly to the polymerization of $\mathrm{BO}$, application of $18 \mathrm{C} 6$ results in the formation of unimodal polymer (16) with markedly higher $M_{n}=11,000$ and very low dispersity $\left(M_{w} / M_{n}=1.03\right)$. Molar mass and dispersity of polymer (17) prepared at much higher $[\mathrm{mon}]_{\mathrm{o}}$ is near the same. It probably results from distinct increase of initiator efficiency, probably due to higher polarity of the medium.

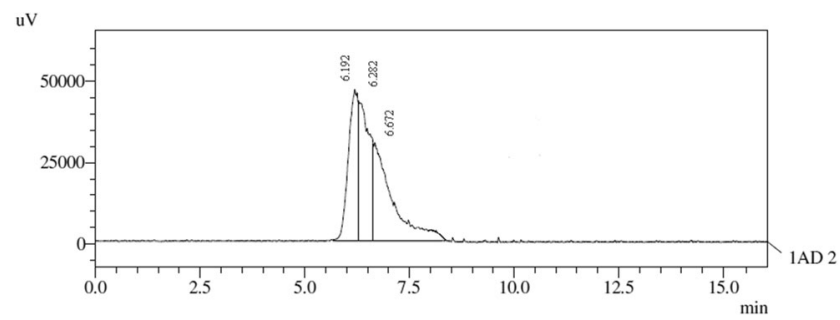

Fig. 8 SEC chromatogram of PBO-diol (10) synthesized by use of anhydrous $\mathrm{KOH}$ activated by $\mathrm{C} 222$ 
Table 4 Characterization of polyether-diols prepared in the polymerization of SO initiated with anhydrous $\mathrm{KOH}$ activated by $18 \mathrm{C} 6$; $[\mathrm{KOH}]_{\mathrm{o}}=[18 \mathrm{C} 6]_{\mathrm{o}}=0.10 \mathrm{~mol} / \mathrm{dm}^{3}$

\begin{tabular}{llllllll}
\hline No. & Initiating system & {$[\text { Monomer }]_{\mathrm{o}}\left(\mathrm{mol} / \mathrm{dm}^{3}\right)$} & $\mathrm{M}_{\text {calc }}$ & Yield (\%) & $\mathrm{M}_{\mathrm{n}}(\mathrm{SEC})$ & $\mathrm{M}_{\mathrm{w}} / \mathrm{M}_{\mathrm{n}}(\mathrm{SEC})$ & Time of reaction (h) \\
\hline 13 & $\mathrm{KOH} / 18 \mathrm{C} 6$ & 2.0 & 4806 & 97 & 3100 & 1.37 & 460 \\
14 & $\mathrm{KOH} / 18 \mathrm{C} 6$ & 5.0 & 12,015 & (a) 46 & 4600 & 1.12 & 550 \\
& & & (b) 54 & 2000 & 1.26 & \\
\hline
\end{tabular}

Addition of small amount of $\mathrm{H}_{2} \mathrm{O}$ results in polymer (18) polymodality and decrease of $\mathrm{M}_{\mathrm{n}}$. Similar effect is observed in the presence of C222 (19).

${ }^{13} \mathrm{C}$ NMR analysis of polymer (15) prepared without ligand indicated signals of unsaturated allyl groups present in substituents in polymer chain at 116.9 and 134.9 ppm (Fig. 11a). However, in the spectrum of polymer (16) obtained in the presence of 18C6 signals of cis-propenyl groups are also observed (Fig. 11b). They consist $12 \%$ of total unsaturation. Stronger signals of cispropenyl groups were shown in the spectrum of polymer (19) synthesized in the presence of C222 (Fig. 11c). They consist $28 \%$ of total unsaturation. Isomerization of side allyl groups to cis-propenyloxy ones was observed previously in anionic polymerization of propylene oxide $[8,13]$ and never in anionic polymerization of AGE
It was proposed, that due to steric hindrance isomerization is mediated with $\mathrm{KOH}$ activated by ligand and not with alkoxide anion of growing chain, as it was reported previously in the polymerization of propylene oxide (PO) [13, 15]. Fig. 12 presents possible course of the reaction.

Molar mass of PIPGE-diol (20) is higher than $\mathrm{M}_{\text {calc }}$, which means that initiator efficiency is high in this system. However, polymerization of BGE (21) is homogeneous, similarly to that of SO (13), which results in high decrease of $M_{n}$ due to chain transfer to water.

In general, in the polymerization of PGE similar effects of ligands on molar masses are observed as in the polymerization of other oxiranes. It is also worth noting, that in the polymerization of MPGE the phenomenon assigned to lability of $\mathrm{CH}_{3} \mathrm{O}$ group bonded to the aromatic ring under influence of $\mathrm{KOH}$ was not observed. ${ }^{13} \mathrm{C}$ NMR spectra of the polymers (27) and (28) indicated

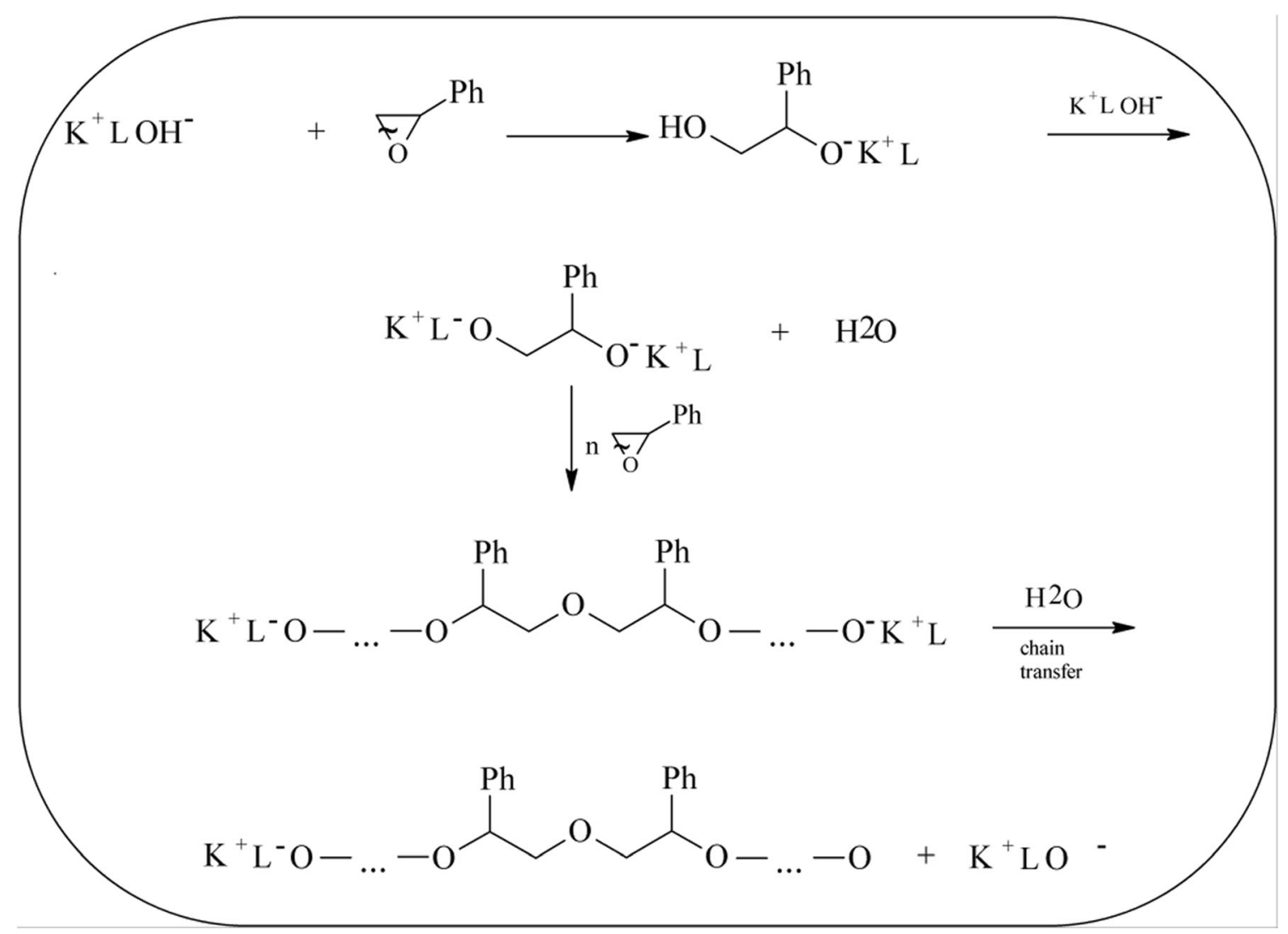

Fig. 9 Polymerization of styrene oxide (SO) initiated with anhydrous $\mathrm{KOH}$ activated by $18 \mathrm{C} 6$ 
Fig. 10 MALDI-TOF specrum of PSO-diol (14) synthesized by use of anhydrous $\mathrm{KOH}$ activated by $18 \mathrm{C} 6$
762.4

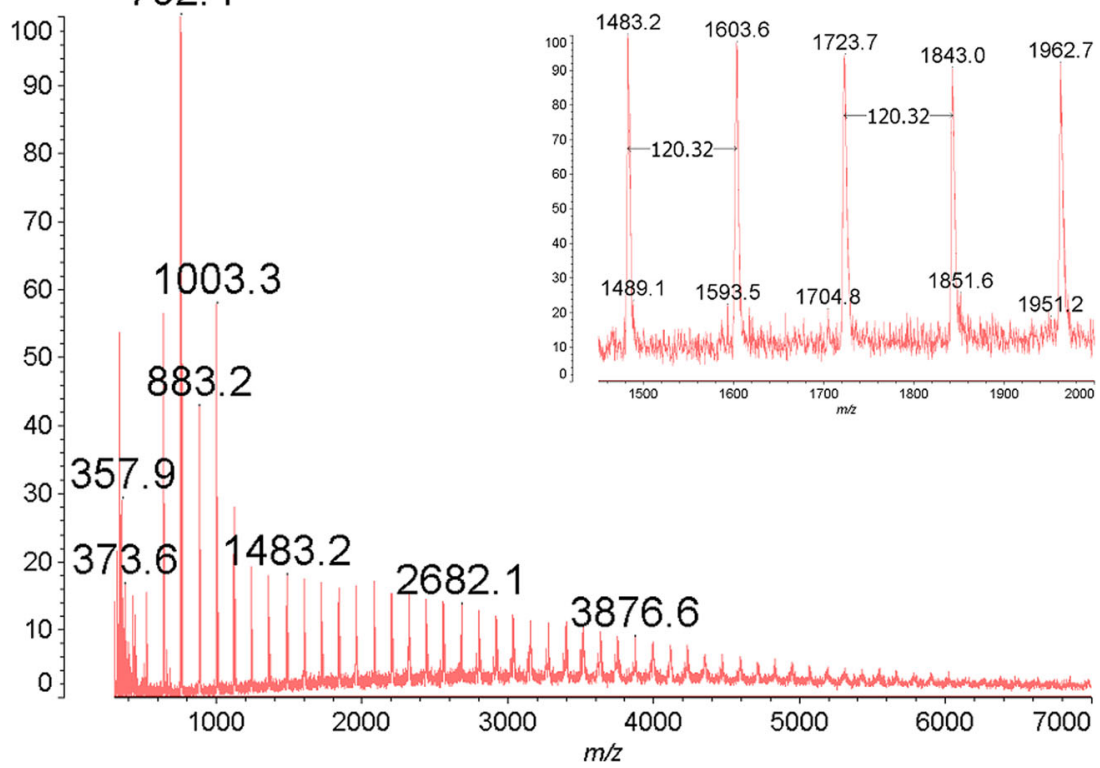

Table 5 Molar masses and dispersities of polyether-diols prepared in the polymerization of allyl glycidyl ether (AGE), isopropyl glycidyl ether (IPGE) and benzyl glycidyl ether (BGE) initiated with anhydrous $\mathrm{KOH} ;[\mathrm{KOH}]_{\mathrm{o}}=[\mathrm{L}]_{\mathrm{o}}=0.10 \mathrm{~mol} / \mathrm{dm}^{3} ;\left[\mathrm{H}_{2} \mathrm{O}\right]_{\mathrm{o}}=0.05 \mathrm{~mol} / \mathrm{dm}^{3}$

\begin{tabular}{|c|c|c|c|c|c|c|c|c|}
\hline No. & Initiating system & {$[\text { Monomer }]_{\mathrm{o}}\left(\mathrm{mol} / \mathrm{dm}^{3}\right)$} & $\mathrm{M}_{\text {calc }}$ & Yield (\%) & $\mathrm{M}_{\mathrm{n}}(\mathrm{SEC})$ & $\mathrm{M}_{\mathrm{w}} / \mathrm{M}_{\mathrm{n}}(\mathrm{SEC})$ & $\operatorname{IE}(f)$ & Time of reaction $(\mathrm{h})$ \\
\hline \multirow[t]{2}{*}{15} & \multirow[t]{2}{*}{$\mathrm{KOH}$} & \multirow[t]{2}{*}{$\operatorname{AGE}(2.0)$} & \multirow[t]{2}{*}{4566} & (a) 75 & 4800 & 1.07 & - & \multirow[t]{2}{*}{180} \\
\hline & & & & (b) 25 & 1300 & 1.27 & - & \\
\hline 16 & $\mathrm{KOH} / 18 \mathrm{C} 6$ & $\operatorname{AGE}(2.0)$ & 4566 & 98 & 11,000 & 1.03 & 0.42 & 120 \\
\hline 17 & $\mathrm{KOH} / 18 \mathrm{C} 6$ & $\operatorname{AGE}(5.0)$ & 11,415 & 97 & 11,500 & 1.04 & 0.99 & 160 \\
\hline \multirow[t]{3}{*}{18} & \multirow[t]{3}{*}{$\mathrm{KOH} / 18 \mathrm{C} 6 / \mathrm{H}_{2} \mathrm{O}$} & \multirow[t]{3}{*}{$\operatorname{AGE}(2.0)$} & \multirow[t]{3}{*}{$4566^{1 /}$} & (a) 25 & 9000 & 1.09 & - & \multirow[t]{3}{*}{410} \\
\hline & & & & (b) 35 & 3600 & 1.12 & - & \\
\hline & & & & (c) 40 & 600 & 1.20 & - & \\
\hline \multirow[t]{2}{*}{19} & \multirow[t]{2}{*}{$\mathrm{KOH} / \mathrm{C} 222$} & \multirow[t]{2}{*}{$\operatorname{AGE}(2.0)$} & \multirow[t]{2}{*}{4566} & (a) 30 & 14,500 & 1.03 & - & \multirow[t]{2}{*}{60} \\
\hline & & & & (b) 70 & 5600 & 1.28 & - & \\
\hline 20 & $\mathrm{KOH} / 18 \mathrm{C} 6$ & IPGE (2.0) & 4644 & 99 & 6000 & 1.35 & 0.77 & 110 \\
\hline 21 & $\mathrm{KOH} / 18 \mathrm{C} 6$ & BGE (2.0) & 6566 & 98 & 3300 & 1.25 & - & 130 \\
\hline
\end{tabular}

${ }^{1 /}$ the influence of chain transfer reaction with $\mathrm{H}_{2} \mathrm{O}$ on molar mass was omitted

exclusively signal of $\mathrm{CH}_{3} \mathrm{O}$ group bonded to the aromatic ring (at $55.7 \mathrm{ppm}$ ); signal of $\mathrm{CH}_{3} \mathrm{OCH}_{2} \mathrm{CH}(\mathrm{R}) \mathrm{O}$ was absent. High initiator efficiency were also calculated for polymerization of phenyl glycidyl ether and $p$-methoxyphenyl glycidyl ether (Table 6).
Polymodality of polyether-diols observed in some studied systems need comments. Such effect depends on the kind of monomer, ligand and water. For example, bimodal PAGE-diol was obtained in the polymerization initiated $\mathrm{KOH}$ without ligand, but three fractions of
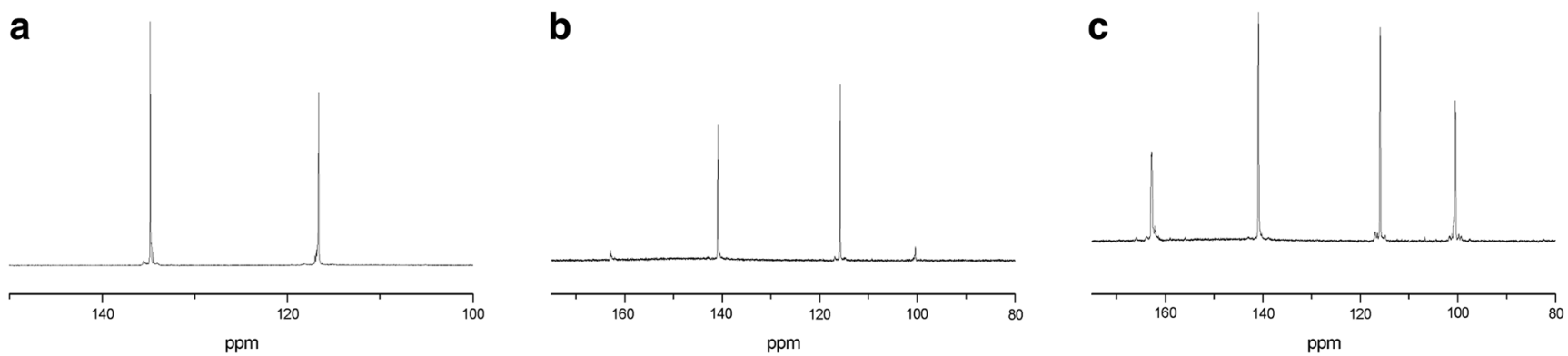

Fig. $11{ }^{13} \mathrm{C}$ NMR spectra of PAGE-diols prepared by use of: (a) anhydrous $\mathrm{KOH}$ without ligand (15); (b) $\mathrm{KOH}$ activated by 18C6 (16); (c) $\mathrm{KOH}$ activated by $\mathrm{C} 222(19)$ 


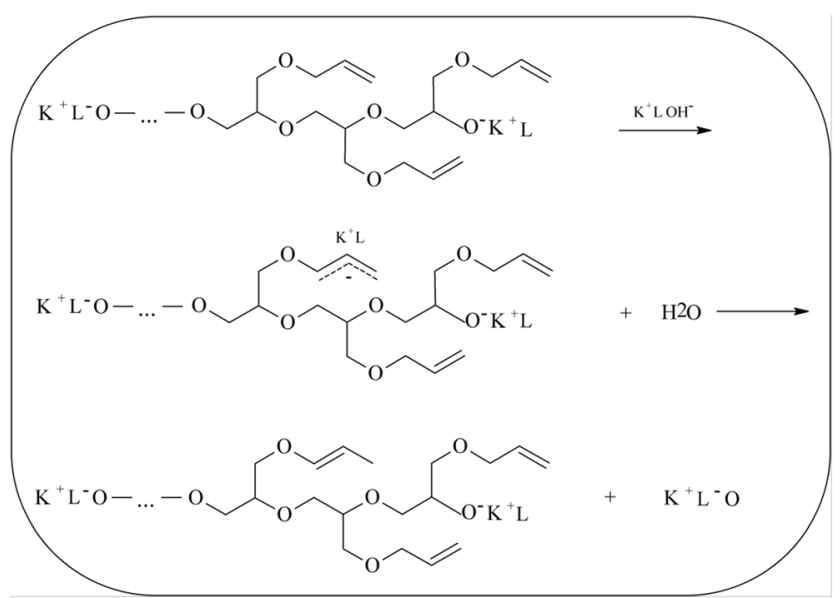

Fig. 12 Isomerization of allyl group to cis-propenyloxy one mediated with anhydrous $\mathrm{KOH}$ activated by ligand (L)

PBO-diol with $\mathrm{KOH}$ activated C222 was formed. Presumably, various ionic species with different reactivities taking part in chain propagation, i.e. contact ion pairs, solvated ion pairs, ligand separated ion pairs and other ionic aggregates are responsible for this phenomenon $[27,28]$. On the other hand, by using for initiation monopotassium salt of dipropylene glycol in THF solution homogeneous polymerization of the same oxiranes were carried out, comparitavely. In these system exclusively unimodal polyether-diols were obtained. Their molar masses determined by SEC are similar to theoretical ones $\left(\mathrm{M}_{\mathrm{n}} \approx \mathrm{M}_{\text {calc }}\right)$. Assuming, some additional experiments applying of the more polar solvents, kinetic study and model reactions may help to better understand the nature and the action of the studied monomers and initiating systems.

\section{Conclusions}

Anhydrous potassium hydroxide $(\mathrm{KOH})$ was applied for ring-opening polymerization of monosubstituted oxiranes in THF at room temperature. Several systems were activated by macrocyclic ligands complexing metal cations. Main characteristic features of these processes are:

- Molar mass $\left(\mathrm{M}_{\mathrm{n}}\right)$, dispersity $\left(\mathrm{M}_{\mathrm{w}} / \mathrm{M}_{\mathrm{n}}\right)$ and modality of the polymers obtained in the presence of $\mathrm{KOH}$ depends strongly on the kind of the monomer, initial concentration of the initiator and the presence and kind of ligand and water;

- $\mathrm{PBO}-$ diols prepared without ligand are bimodal and $\mathrm{M}_{\mathrm{n}}>\mathrm{M}_{\text {calc }}$; after addition of $18 \mathrm{C} 6$ the polymers are unimodal and unexpectedly they have markedly higher $M_{n}(13700-15,800)$ and very low dispersity $\left(\mathrm{M}_{\mathrm{w}} / \mathrm{M}_{\mathrm{n}}=1.04-1.08\right)$;

- $\mathrm{M}_{\mathrm{n}}$ of PBO-diols decreases with increasing of $[\mathrm{KOH}]_{\mathrm{o}}$ and only slightly increase at $[\mathrm{BO}]_{\mathrm{o}}=$ $2.0-9.0 \mathrm{~mol} / \mathrm{dm}^{3}$, probably due to increase of $[\mathrm{KOH}]_{\mathrm{o}}$ activated $18 \mathrm{C} 6$ in much more polar reaction mixture; addition of $\mathrm{C} 222$ causes lowering of $\mathrm{M}_{\mathrm{n}}$ for PBO-diols; similar effects were observed for PAGEdiols and PPGE-diols;

- PSO-diols prepared at low $[\mathrm{SO}]_{\mathrm{o}}$ is unimodal, whereas at higher $[\mathrm{SO}]_{\mathrm{o}}$ is bimodal and the systems are homogeneous;

- In the polymerization of SO, PGE, MPGE and BGE initiator efficiency is high, resulting in $\mathrm{M}_{\mathrm{n}}<\mathrm{M}_{\text {calc }}$ and chain transfer to water formed during initiation;

- In all obtained polymers unsaturation was not observed; it means, that chain transfer to monomer was absent;

- Polymodality of some polymers can be explained by the formation of various ionic species propagating with different rate constants;

- Some of prepared polyether-diols could be useful for synthesis of new polyurethane elastomers due to their relatively high $\mathrm{M}_{\mathrm{n}}$ and low dispersity.

Table 6 Molar masses and dispersities of polyether-diols prepared in the polymerization of phenyl glycidyl ether (PGE) and $p$-methoxyphenyl glycidyl ether (MPGE) initiated with anhydrous $\mathrm{KOH} ;[\mathrm{KOH}]_{\mathrm{o}}=[\mathrm{L}]_{\mathrm{o}}=0.10 \mathrm{~mol} / \mathrm{dm}^{3} ;\left[\mathrm{H}_{2} \mathrm{O}\right]_{\mathrm{o}}=0.05 \mathrm{~mol} / \mathrm{dm}^{3}$

\begin{tabular}{|c|c|c|c|c|c|c|c|}
\hline No. & Initiating system & {$[\text { Monomer }]_{\mathrm{o}}\left(\mathrm{mol} / \mathrm{dm}^{3}\right)$} & $\mathrm{M}_{\text {calc }}$ & Yield (\%) & $\mathrm{M}_{\mathrm{n}}(\mathrm{SEC})$ & $\mathrm{M}_{\mathrm{w}} / \mathrm{M}_{\mathrm{n}}(\mathrm{SEC})$ & Time of reaction (h) \\
\hline 22 & $\mathrm{KOH}$ & PGE (2.0) & 6000 & 98 & 4300 & 2.54 & 120 \\
\hline 23 & $\mathrm{KOH} / 18 \mathrm{C} 6$ & PGE (2.0) & 6000 & 99 & 6400 & 1.36 & 80 \\
\hline 24 & $\mathrm{KOH} / 18 \mathrm{C} 6 / \mathrm{H}_{2} \mathrm{O}$ & PGE (2.0) & $6000^{1 /}$ & $\begin{array}{l}\text { (a) } 30 \\
\text { (b) } 70\end{array}$ & $\begin{array}{l}10,000 \\
4000\end{array}$ & $\begin{array}{l}1.01 \\
1.35\end{array}$ & 320 \\
\hline 25 & $\mathrm{KOH} / 18 \mathrm{C} 6$ & PGE (5.0) & 15,000 & 98 & 5400 & 1.29 & 220 \\
\hline 26 & $\mathrm{KOH} / \mathrm{C} 222$ & PGE (2.0) & 6000 & $\begin{array}{l}\text { (a) } 80 \\
\text { (b) } 20\end{array}$ & $\begin{array}{l}3000 \\
600\end{array}$ & $\begin{array}{l}1.25 \\
1.11\end{array}$ & 50 \\
\hline 27 & $\mathrm{KOH}$ & $\operatorname{MPGE}(2.0)$ & 7200 & $\begin{array}{l}\text { (a) } 90 \\
\text { (b) } 10\end{array}$ & $\begin{array}{l}5300 \\
2200\end{array}$ & $\begin{array}{l}1.05 \\
1.07\end{array}$ & 160 \\
\hline 28 & $\mathrm{KOH} / 18 \mathrm{C} 6$ & MPGE (2.0) & 7200 & 99 & 4400 & 1.23 & 95 \\
\hline
\end{tabular}

1/ The influence of chain transfer reaction with $\mathrm{H}_{2} \mathrm{O}$ on molar mass was omitted 


\section{Compliance with ethical standards}

Conflict of interest The authors declare that they have no conflict of interest.

Open Access This article is distributed under the terms of the Creative Commons Attribution 4.0 International License (http:// creativecommons.org/licenses/by/4.0/), which permits unrestricted use, distribution, and reproduction in any medium, provided you give appropriate credit to the original author(s) and the source, provide a link to the Creative Commons license, and indicate if changes were made.

Publisher's note Springer Nature remains neutral with regard to jurisdictional claims in published maps and institutional affiliations.

\section{References}

1. Gosa KI, Uricanu V (2002) Emulsions stabilized with PEO-PPOPEO block copolymers and silica. Colloids Surf A Physicochem Eng Asp 197:257-269

2. Mathur AM, Drescher B, Scranton AB, Klier J (1998) Polymeric emulsifiers based on reversible formation of hydrophobic units. Nature 392:367-370

3. Herzberger J, Niederer K, Pohlit H, Seiwert J, Worm M, Wurm FR, Frey H (2016) Polymerization of ethylene oxide, propylene oxide, and other alkylene oxides: synthesis, novel polymer architectures, and bioconjugation. Chem Rev 116:2170-2243. https://doi.org/10. 1021/acs.chemrev.5b00441

4. Zhang ZQ, Xu GY, Wang F, Dong SL, Li Y (2004) Characterization and demulsification of poly(ethylene oxide)-block-poly(propylene oxide)-block-poly(ethylene oxide) copolymers. J Colloid Interface Sci 277:464-470

5. Jeong B, Bae YH, Lee DS, Kim SW (1997) Biodegradable block copolymers as injectable drug-delivery systems. Nature 388:860862

6. Izukawa T, Kunihiro T, Nishikawa A (Eds.) M.C.I. US Patent 5, 916, 994, 1999

7. Cendejas G, Flores-Sandoval CA, Huitrón N, Herrera R, Zamudio-Rivera LS, Beltrán HI, Vázquez F (2008) Theoretical and experimental studies of the initiator influence on the anionic ring opening polymerization of propylene oxide. J Mol Struct 879:40-52

8. Ionescu M (2005) Chemistry and Technology of Polyols for Polyurethanes, Rapra Technology Limited, Shawbury, Shrewsbury, Shropshire and references therein

9. Becker H, Wagner G (1984) Zur Übertragungsreaktion bei der anionichen Polymerisation von Oxiranen VI. Zum Einfluß von Kronenetherzusätzen auf die Polymerisation von Propylenoxid. Acta Polym 35:28-32

10. Yu GE, Heatley F, Booth C, Bleas TG (1994) Anionic polymerization of propylene oxide: isomerization of allyl ether to propenyl ether end groups. J Polym Sci A Polym Chem 32: $1131-1135$

11. Ding J, Price C, Booth C (1991) Use of crown ether in the anionic polymerization of propylene oxide-1. Rate of polymerization. Eur Polym J 27:891-894

12. Pierre LES, Price CC (1956) The room temperature polymerization of propylene oxide. J Am Chem Soc 78(14):34323436. https://doi.org/10.1021/ja01595a047
13. Steiner EC, Pelletier RR, Trucks RO (1964) A study of the polymerization of propylene oxide catalyzed by anhydrous potassium hydroxide. J Am Chem Soc 86:4678-4686

14. Pluciński J, Matyschok H, Janik R, Prystasz H (1981) Polymerisation des Propylenoxids in Anwesenheit von fastem Kaliumhydroxid. Angew Macromol Chem 97:35-50

15. Grobelny Z, Matlengiewicz M, Jurek J, Michalak M, Kwapulińska D, Swinarew A, Schab-Balcerzak E (2013) The influence of macrocyclic ligands and water on propylene oxide polymerization initiated with anhydrous potassium hydroxide in tetrahydrofuran. Eur Polym J 49:3277-3288

16. Wegner G, Brandt M, Duda L, Hofmann J, Kleszczewski B, Koch D et al (2001) Trends in industrial catalysisin the polyurethane industry. Appl Catal A General 221:303-305

17. Grobelny Z, Matlengiewicz M, Jurek-Suliga J, Golba S, Skrzeczyna K, Kwapulińska D (2017) Ring opening polymerization of styrene oxide initiated with potassium alkoxides and hydroxyalkoxides activated by 18 -crown- 6 : determination of mechanism and preparation of new polyether-polyols. Polym Bull 74:4763-4780

18. Zhilkova K, Mateva R, Kyulavska M (2017) Copolymers of $\varepsilon$ caprolactam and polypropylene oxide via anionic polymerization: synthesis and properties. J Polym Res 24:162-172. https://doi.org/ 10.1007/s10965-017-1324-2

19. Stolarzewicz A (1983) Influence of the structure of chlorophenyl 2, 3 -epoxypropyl ethers on their reactivity in ionic polymerization. Macromol Chem 184:1577-1584

20. Stolarzewicz A (1983) Application of correlation equations for determining the solvent effect in the heterogeneous polymerization of o-chlorophenyl glycidyl ether initiated by potassium hydroxide. Acta Polym 34:210-212

21. Lambda NMK, Woodhouse KA, Cooper CL (1998) Polyurethanes in biomedical applications. CRC Press, New York

22. Meier-Westhues U (2007) Polyurethanes-coatings, adhesives and Sealants, Vincentz Network Gmbh, Hannover

23. Malmsten M, Linse P, Zhang KW (1993) Phase behavior of aqueous poly(ethylene oxide)/poly(propylene oxide) solutions. Macromolecules 26:2905-2910

24. Dimitrov P, Rangelov S, Dworak A, Tsvetanov CB (2004) Synthesis and associating properties of poly(ethoxyethyl glycidyl ether)/poly(propylene oxide) triblock copolymers. Macromolecules 37:1000-1008

25. Brown CA (1974) Saline hydrides and superbases in organic reactions. VII. Potassium hydride, highly active new hydride reagent. Reactivity, applications, and techniques in organic and organometallic reactions. J Org Chem 39:3913-3918

26. Siggia $\mathrm{S}$ (1963) Quantitative organic analysis via functional groups. Wiley, New York, p 241

27. Penczek S, Cypryk M, Duda A, Kubisa P, Słomkowski S (2007) Living ring-opening polymerizations of heterocyclic monomers. Prog Polym Sci 32:247-282

28. Szwarc M (ed) (1974) Ion and ion pairs in organic reactions. Wiley, New York

29. Izatt RM, Bradshaw JS, Nielsen SA, Lamb JD, Christensen JJ (1985) Thermodynamic and kinetic data for cation-macrocycle interaction. Chem Rev 85:271-339 